\title{
Designing a Knowledge Mobilization Strategy: Leading through Influence
}

\author{
Dr. Steven Reid \\ Superintendent \\ York Region District School Board \\ Newmarket, Canada \\ DrStevenReid@outlook.com
}

\begin{abstract}
As district leaders consider professional learning opportunities for educators, mobilizing new thought and actions across an entire system is a vexing challenge. Classroom-based learning may unfortunately be viewed as juxtaposed to district-based learning. It becomes essential for district leaders to develop knowledge mobilization strategies which provide a framework for any district-wide focus or initiative. In doing so, opportunities for knowledge influencers to interact with each other at various levels of the educational system are intentionally enhanced, that is, at the classroom, school, and district levels. Knowledge creating groups are thereby encouraged to challenge the status quo and promote innovation.
\end{abstract}

\section{Introduction}

Successful educational systems are fundamentally responsible to ensure that students gain the knowledge and skills necessary to be successful today and in the future. For the purpose of this article, an educational system is considered the collective efforts of individuals within a district to ultimately support the learning of all students. As the world around each student changes, a dedicated and coordinated effort to mobilize new knowledge is required to meet ever shifting demands. The concept of 'going to scale' involves changes of thought and practice that extends and amplifies across a system and becomes embedded in the system's culture over time. For this to occur, Coburn (2003) and Cordingley and Bell (2007) identify several dimensions that are required:

- Goal and purpose - the proposed reasons and outcomes for the change in thought and practice;

- Depth - depth of change in thought and practice moves beyond the superficial;

- Sustainability - change in thought and practice can withstand competing demands and other challenges over time;

- Spread - number of staff involved in change in thought and practice; and

- Ownership - staff take internal ownership for the change in thought and practice.

The initial stages of any new initiative are often embraced with enthusiasm, energy, and commitment. Why? As a new initiative rolls out, it is regularly provided with funding, professional learning opportunities, and offered to a small group of keen early adapters and those already committed to the cause (Bulkley, Christman, Goertz, \& Lawrence, 2010; Phillips, 2003). 
Hence, the ever present challenge for district leaders (e.g., persons in district-level positions such as directors, supervisory officers, district principals, and consultants) is to mobilize new thought and actions with each and every school and classroom across an entire system.

\section{Overview}

To illustrate how the realm of theory is transformed into practice, the planning and actions of York Region District School Board (YRDSB) leaders at both the district and school level are outlined below. This article describes the initial stages of implementing a knowledge mobilizing strategy called the Early Years and First Nations, Métis, and Inuit (FNMI) Literacy through the Collaborative Inquiry Initiative (CII). This initiative involved the collaboration of various departments within both Student Services along with Curriculum and Instructional Services, including expert staff from Early Years, FNMI, Leadership Development, Reading Recovery®, Special Education, and Speech-Language Pathology. The focus of this endeavor was to mobilize FNMI teachings within Kindergarten to grade two (K-2) classrooms. With more than 150 schools that have K-2 classrooms in YRDSB and only five district FNMI staff, maintaining regular connections to each classroom posed a challenge. For these reasons, energies were directed to a knowledge mobilization strategy involving collaboration and partnerships.

The early stages of this CII began as system needs were compared with system resources. The necessity to embed FNMI teachings within the classroom was deemed an essential priority. The Ontario FNMI Education Policy Framework (2007) highlighted a sense of urgency by detailing significant gaps in educational attainment. These gaps were evident at the elementary, secondary and post-secondary levels while comparing Aboriginal and non-Aboriginal students. Overall goals entailed fundamental changes to the way educators approached teaching of FNMI peoples in the past, present, and future. To support organizational change, learning became the work (Fullan, 2008). With the enormity of this endeavor, a yearlong focus with a few projects sprinkled here and there within the district was not an option. Therefore, a four to five year knowledge mobilization strategy was required to realize a vision of equity by supporting professional learning at all levels of the district.

\section{Professional Learning}

Research continues to confirm that educators prefer professional learning to support the effectiveness of their practice and the improved learning of their students (Scott, Webber, Aitken, \& Lupart, 2011). As educational systems strive for excellence, a systemic belief that each educator can continuously learn and improve on professional practice must be embedded in the culture of the systems (Hargreaves \& Shirley, 2012). Furthermore, the OECD (2013) recognizes the importance of "learning leadership," in which learning is at the heart of an educational system and where leaders nurture environments that thrive on learning at all levels of the system (p. 51). In order to provide focus to the complex concept of mobilizing knowledge throughout a system, district leaders planned professional learning under three broad constructs: leadership; pedagogy (i.e., instruction); and content knowledge (e.g., FNMI cultures and histories). Subsequently, district leaders believed that by supporting these three constructs 
within a mobilization strategy, the learning of staff and students would be demonstrated in classrooms across the district.

Leadership. The success of a knowledge mobilization strategy is dependent on the work of knowledge influencers, those who regularly access knowledge creating groups throughout the various levels of the system including school and district levels. These formal and informal leaders are critical to influencing the mobilization of new knowledge (Reid, 2014). With this in mind, district leaders discussed how FNMI knowledge, in combination with sound early years instructional strategies, would be mobilized throughout the district. During the first year, approximately $1 / 5$ of the elementary schools across the district participated in the initiative. In each school, teams of eight educators from the K-2 grades joined in district- and school-based learning. The teams included five classroom teachers, as well as three teacher leaders. The teacher leaders comprised of a literacy lead, equity lead, and special education resource teacher. Each brought specialized expertise when investigating teaching and learning. For example, the special education resource teachers regularly considered the accommodations and modifications required to help all students access FNMI teachings through literacy. Importantly, these teacher leaders were provided with facilitation training to further develop leadership skills. These skills were crucial to influence the collaborative inquiry processes at the school level. As teams of teachers gathered to plan and analyze their own practice, the collaborative inquiry was facilitated by teacher leaders. Principals and vice-principals were also invited to all district level professional leaning opportunities. Although not mandatory, several attended and brought new knowledge to their regional administrator meetings to further promote mobilization of thought and action.

Pedagogy. One of the most important aspects of collaborative inquiry processes involves critically analyzing pedagogy, i.e., instructional practices. A trusting environment is necessary for educators to openly share their practices in front of others (Earl \& Timperley, 2009). Additionally, any questions or challenges to current and future practices must not be considered an evaluation of the educator. Throughout their careers, educators build a repertoire of instructional practices that are enacted consciously based on explicit knowledge or subconsciously based on tacit knowledge (Nonaka \& Takeuchi, 1995; Polanyi, 1962). District research indicates that knowledge influencers play a key role in modeling the difficult task of critiquing instructional practices and challenging beliefs and biases during collaborative inquiry processes (Reid, 2014). In this CII, district leaders acknowledged that deconstructing instructional practices, beliefs, and understandings in teams would involve a difficult exploration. During this endeavour, educators were asked to question the soundness of pedagogy based on context (e.g., strengths, needs and interests of students) and consider the mindsets that underpin the actions to inform and change future practices.

Content Knowledge. In Ontario, much like in other parts of Turtle Island (i.e., North America), resources and educators' content knowledge of FNMI histories and cultures is relatively thin (Toulouse, 2011). When educators were brought together during this CII, most were anxious about their limited understanding of FNMI perspectives and particular learning styles of FNMI students. Researchers have espoused the critical interplay between teacher, student, and content in the instructional core of the classroom (City, Elmore, Fiarman, \& Teitel, 2009). It was not surprising to find that participants in this CII often felt helpless to provide 
engaging and purposeful learning opportunities for students without FNMI content knowledge. To support the building of foundational content knowledge, district leaders considered both experts and resources. During the first year, Professor Pamela Toulouse was brought in to launch the initiative. As an expert, she brought FNMI histories and perspectives with evidencebased and promising instructional practices to support both FNMI and non-FNMI student learning. A variety of Ontario Ministry of Education publications were supplied to participants, as well, FNMI classroom literacy resources and Dr. Toulouse's book were purchased for students and teachers. In the second year of the initiative, district leaders also engaged Professor Susan Dion as an expert. She brought not only the histories of residential schools to educators, but Dr. Dion also involved participants in considering 'teaching in a good way,' that is, ensuring educators did not unknowingly take part in cultural appropriation.

\section{Knowledge Mobilization Strategy}

In order to create an effective knowledge mobilization strategy across a district, considerations must be given to where knowledge exists at different levels within and beyond the system. District leaders can then cultivate knowledge building opportunities at these levels.

Knowledge influencers would then intersect with each other, resulting in knowledge creation and mobilization throughout the system. To plan the CII, the existence of knowledge and learning was identified at four levels: 1) external (e.g., partnership with ministries and universities); 2) district (e.g., large-scale professional learning opportunities, conferences); 3) clusters of specialists (e.g., special education resource teachers, content specialists); and 4) school. Learning opportunities at each of the levels was reviewed and plans were carefully developed to support consistent opportunities for knowledge dissemination, co-creation, and mobilization.

External Level: Partnerships. The Ministry of Education was a vital external partner in several instances throughout this CII and provincial FNMI endeavours. In attempts to support knowledge creation within a system, time was a critical component. Researchers have strongly argued that time is required to allow teachers to come together to investigate student data, consider promising instructional practices and monitor results (Ermeling, 2010; Gallimore, Ermeling, Suanders, \& Goldenberg, 2009; Louis, Leithwood, Wahlstrom, \& Anderson, 2010; Reid, 2013). Fortunately, the ministry offered FNMI funding to provide time for teachers to engage in this CII and subsidized the district FNMI leadership positions. Furthermore, ministry staff supported various FNMI initiatives in YRDSB (e.g., FNMI Steering Committee) to promote consistent messaging and understandings. As previously highlighted, university staff also offered expert knowledge on FNMI histories and cultures. Other essential external partners in this CII included a local First Nation Community (Chippewas of Georgina Island), as well as First Nation elders. These honoured partners ensured that all participants were immersed in Indigenous knowledge that was accurate and respectful. Each district session began with an elder led ceremonial opening of smudging, giving thanks, and honouring the traditional land. These partners offered many gifts of knowledge through experiential opportunities for educators to learn and share with others.

District Level: Knowledge Dissemination. In of itself, bringing educators together on a large scale for professional learning does not affect change in practice at the classroom level (Katz \& Dack, 2013). However, large scale professional learning can be effective when 
delivered in alignment with other forms of learning to expedite the dissemination of essential content knowledge required for further inquiry at the school and classroom levels (Reid, 2014). District leaders felt strongly that this CII could not take place in a FNMI knowledge vacuum. To gain an initial momentum in this CII, all participants were brought together for a day to convey the following: scope of the initiative; framework for collaborative inquiry; essential FNMI understandings; and FNMI resources to be utilized throughout the initiative. Throughout the year, participants shared their learnings and resources via a virtual repository. Interestingly, Scott and Scott (2010) have noted that when teachers share their practices and resources online, the quality of the materials posted improves. The CII's digital space allowed participants to disseminate and access knowledge throughout the year. A second district level gathering of all participants occurred at the end of the year. Artifacts of learning were brought to the culminating event including pictures, videos, and student work samples. Staff presented their FNMI learning journeys to support the sharing of knowledge. Learning summaries from each school were posted on the digital space highlighting the inquiry question of investigation, alignment to curriculum, actions taken, impact on student learning, change in educator practice, and reflections.

Clusters of Specialists Level: Leadership Development. Three teacher leaders from each school were brought together to further develop their facilitation skills. The teacher leaders were already positioned within their schools to be knowledge influencers. Based on their roles, they had access to professional learning at the district level and were expected to bring knowledge back into their schools in an attempt to mobilize effective and promising practices in all classrooms (Reid, 2014). However, bringing teachers together to reflect upon current practice has been found to be contentious at times (Earl \& Timperley, 2009). The CII went beyond the investigation of instructional practices by requiring educators to deeply reflect upon culturally responsible and relevant pedagogy, positions of privilege, stereotypes, prejudice, discrimination, and self-esteem (Ladson-Billings, 2006). District leaders and knowledge influencers endorsed safe environments in which collective questioning and risk-taking did not involve the fear of blame or reprimand. In doing so, it was felt that continued dialogue set the foundation for innovative thought.

School Level: Professional Learning Processes. As part of this CII, funds were provided to allow the eight participants from each school to gather and create knowledge, hence becoming a knowledge creating group at the school level. These groups were a foundational component of creating knowledge by using data and consistently challenging current practices, knowledge, and preconceptions. A fertile ground for experimentation, innovation, and cocreation of new knowledge was readily available in classrooms while educators interacted with students. Furthermore, knowledge influencers and knowledge creating groups played an important role in challenging the status quo to stimulate reflection and professional growth. Similar to other district research, teams engaged in reviewing relevant curriculum, assessing student work, reflecting on practices, investigating student thinking, and modifying instructional strategies (Reid, 2014). This often involved participating in the "4 Cs," that is, co-planning, coteaching, co-debriefing, and co-reflecting (Belchetz \& Witherow, 2014). Ultimately, the processes of collaborative inquiry enabled educators to consider their role in the progress of students. Consequently, instead of blaming student achievement on external factors, educators deeply examined the evolution of their own practice and its impact on students. 


\section{Recommendations}

Systemic Promotion of Cultures of Inquiry. Collaborative inquiry processes conceivably mirror aspects of FNMI cultures, often reliant on the passing of traditional knowledge through oral exchange (Senge, 2006). Collaborative inquiry is founded on dialogue in which participants suspend their beliefs, assumptions, and understandings for others to contemplate. It is critical for district leaders and knowledge influencers to explicitly promote and model that collaborative inquiry can only be accomplished in a caring and professional way. For example, district leaders set the stage for this initiative by connecting to the Grandfather Teachings, specifically the teaching of humility. District leaders identified that they personally had much to learn and that together, staff would learn in a respectful manner. Furthermore, it was highlighted that historical atrocities would be discussed (e.g., residential schools). In doing so, educators would consider ... "the impact that colonial history has had on Aboriginal culture, and the crucial role that education plays in healing and self-determination" (Toulouse, 2011, p. 3).

As educational systems attempt to promote cultures of inquiry, norms of collaboration and non-judgment must be carefully established to support positive and constructive cultures of trust, risk-taking, and learning. Although each participant of collaborative inquiry will bring specific expertise to the work, a learning stance must become the norm. Importantly in this CII, district leaders explicitly stated that mistakes would be made along the journey. For example, first year participants were provided many resources with limited initial understanding of 'teaching in a good way.' After reflecting on this gap, second year participants were provided with guidance early in the professional learning that allowed educators to plan lessons with wisdom about cultural respect instead of cultural appropriation.

Utilizing Knowledge Influencers to Promote Coherence and Innovation. The dialectic between district-based learning versus classroom-based learning should not be reinforced within a knowledge mobilization strategy. Instead, educators must be provided with opportunities to learn at various levels within and beyond the system. Knowledge influencers play a central role in supporting collaborative inquiry processes and mobilizing knowledge throughout the system. New ways of thinking and working, as well as next steps determined at the district level are brought back to school-based knowledge creating groups. In doing so, coherence is strengthened between schools, specifically, coherence of beliefs, thought, and actions. In this CII, coherence was not promoted at the expense of innovative thought as knowledge influencers encouraged educators to stretch their current understandings to support each and every student. While cultivating a knowledge mobilization strategy, educators must be provided with a balance between current knowledge of evidence-based practices and collective autonomy to explore innovative and promising practices for the future. 


\section{References}

Belchetz, D., \& Witherow, K. (2014). Ontario district embraces an evolving approach to learning. Journal of Staff Development, 35(1), 18-30.

Bulkley, K. E., Christman, J. B., Goertz, M. E., \& Lawrence, N. R. (2010). Building with benchmarks: The role of the district in Philadelphia's benchmark assessment system. Peabody Journal of Education, 85(2), 186-204. doi:10.1080/01619561003685346

City, E., Elmore, R., Fiarman, S., \& Teitel, L. (2009). Instructional rounds in education: A network approach to improving teaching and learning. Cambridge, MA: Harvard Education Press.

Coburn, C (2003, August). Rethinking scale: Moving beyond numbers to deep and lasting change. Educational Researcher, 32(6), 3-12.

Cordingley, P., \& Bell, M. (2007). Transferring learning and taking innovation to scale. London: CUREE.

Earl, L. M., \& Timperley, H. (2009). Understanding how evidence and learning conversations work. In L. M. Earl, \& H. Timperley (Eds.), Professional learning conversations: Challenges in using evidence for improvement (pp. 1-12). LaVergne, TN: Springer.

Ermeling, B. A. (2010). Tracing the effects of teacher inquiry on classroom practice. Teaching and Teacher Education, 26(3), 377-388. doi:10.1016/j.tate.2009.02.019

Fullan, M. (2008). The six secrets of change: What the best leaders do to help their organizations survive and thrive. San Francisco, CA: Jossey-Bass.

Gallimore, R., Ermeling, B. A., Saunders, W. M., \& Goldenberg, C. (2009). Moving the learning of teaching closer to practice: Teacher education implications of school-based inquiry teams. The Elementary School Journal, 109(5), 537-553. doi:10.1086/597001

Hargreaves, A. \& Shirley, D. (2012). The global fourth way: The quest for educational excellence. Thousand Oaks, CA: Corwin.

Katz, S., \& Dack, L, A. (2013). Intentional Interruption: Breaking Down Leanring Barriers to Transform Professional Practice. Thousand Oaks, CA: Corwin.

Ladson-Billings, G. (2006). It's not the culture of poverty, it's the poverty of culture: The problem with teacher education. Anthropology and Education Quarterly. 37(2), 104-109. doi:10.1525/aeq.2006.37.2.104

Louis, K. S., Leithwood, K., Wahlstrom, K. L., \& Anderson, S. E. (2010). Learning from leadership: Investigating the links to improved student learning. Report to the Wallace 
Foundation. Retrieved from The University Minnesota website: http://www.cehd.umn.edu/.

Nonaka, I. A., \& Takeuchi, H. A. (1995). The knowledge-creating company: How Japanese companies create the dynamics of innovation. Oxford, NY: Oxford University Press.

OECD. (2013). Leadership for 21 $1^{\text {st }}$ century learning: Educational research and innovation. Paris, FR: OECE Publishing. doi:10.1787/9789264205406-en

Ontario Ministry of Education. (2007). Ontario FNMI Education Policy Framework. Toronto, ON: Ontario Ministry of Education.

Phillips, J. (2003). Powerful learning: Creating learning communities in urban school reform. Journal of Curriculum and Supervision, 18(3), 240-258.

Polanyi, M. (1962). Tacit knowing: Its bearing on some problems of philosophy. Reviews of Modern Physics, 34(4), 601-616.

Reid, S. (2013). The leader's role in strategic knowledge creation and mobilization. International Journal for Leadership in Learning, 1(1), 1-53.

Reid, S. (2014). Knowledge influencers: Leaders influencing knowledge creation and mobilization. Journal of Educational Administration, 52(3), 332-357. doi:10.1108/JEA01-2013-0013

Scott, D. E., \& Scott, S. (2010). Innovations in the Use of Technology and Teacher Professional Development. In J. O. Lindberg \& A. D. Olofsson (Eds.), Online learning communities and teacher professional development: Methods for improved education delivery (pp. 169-189. Hershey, PA: IGI Global.

Scott, S., Webber, C. F., Aitken, N., \& Lupart, J. (2011). Developing teachers' knowledge, beliefs, and expertise: Findings from the Alberta student assessment study. The Educational Forum, 75(2), 96-113. doi:10.1080/00131725.2011.552594

Senge, P. M. (2006). The fifth discipline: The art and practice of the learning organization (Rev. ed.). New York, NY: Doubleday.

Toulouse, P. R. (2011). Achieving aboriginal student success: A guide for $k$ to 8 classrooms. Winnipeg, MB: Portage and Main.

\section{Author Biography}

Steven Reid is currently on secondment from the York Region District School Board (YRDSB) with Ontario's Ministry of Education. At YRDSB, he was the Superintendent of Student Services with the primary role of supporting special education within the region. One of 
his portfolios also included First Nation, Métis, and Inuit education. He has been able to engage in leadership development, curriculum implementation, and systems change through various positions including Superintendent of Education, Senior Specialist with the Leadership Development Branch of the Ministry of Education, and Central Coordinating Principal. His current interests include investigations of leaders influencing knowledge creation and mobilization in educational systems. 